\title{
A novel carbon cycle turbulence index identifies environmental and ecological perturbations
}

\author{
Z.-H. Li', Z. Guo², Z.-Q. Chen ${ }^{2 *}$, S.W. Poulton ${ }^{1,3}$, Y. Bao ${ }^{4}$, \\ L. Zhao ${ }^{1 *}$, F.-F. Zhang ${ }^{5}$
}

Abstract

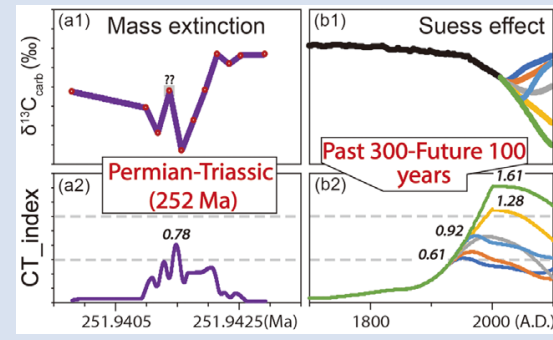

Earth's history has been characterised by complex interactions between life and the environment, which are often difficult to resolve. Here, we propose a new carbon cycle turbulence index $\left(\mathrm{CT}_{\text {index }}\right)$, based on the carbonate-carbon isotope $\left(\delta^{13} \mathrm{C}_{\text {carb }}\right)$ record, to measure the extent of environmental perturbation over the last billion years. The $\mathrm{CT}_{\text {index }}$ trend is closely linked to Phanerozoic biotic extinction rates (ERs), as calculated from a palaeobiology database, supporting a strong environmental control on biotic ERs. We use the empirical $\mathrm{CT}_{\text {index }}-\mathrm{ER}$ relationship to compare the extent of environmental perturbation due to greenhouse gas emissions with that during the Permian-Triassic (PTr) transition ( 252 Ma), representing the most severe mass extinction of the Phanerozoic. At the current peak of fossil fuel emissions, the $\mathrm{CT}_{\text {index }}$ indicates a moderate future environmental perturbation. However, if fossil fuel emissions increase into the next century, a pronounced $\mathrm{CT}_{\text {index }}$ peak greater than that which occurred during the PTr transition is indicated, which suggests the potential for a severe "sixth mass extinction" in the future.

Received 3 October 2021 | Accepted 6 December 2021 | Published 30 December 2021

\section{Introduction}

The evolution of life on Earth has been punctuated by extreme environmental/climatic events, often leading to mass extinctions (Chen and Benton, 2012; Rothman, 2017). Carbon cycle perturbations, global warming or cooling, and widespread anoxia have all played major roles in shaping the course of biotic macroevolution (Payne et al., 2020). However, there is no general model that encompasses the range of scenarios documented by the geological record. For example, in terms of global $\delta^{13} \mathrm{C}$ records, negative (e.g., end Permian) and positive (e.g., end Ordovician) excursions have both been linked to biotic extinctions (Fan et al., 2020). Thus, while major biotic events were linked to intervals of environmental perturbation and ecologic disturbance, they were not universally driven by one particular environmental process. However, there are no reliable proxies for measuring the extent of carbon cycle instability and associated environmental stress through Earth history.

Here, we develop a carbon cycle turbulence index $\left(\mathrm{CT}_{\text {index }}\right)$ to measure perturbations in the $\delta^{13} \mathrm{C}_{\text {carb }}$ record (Cramer and Jarvis, 2020) over the last 1,000 Myr. The $\mathrm{CT}_{\text {index }}$ emphasises perturbations to the carbon cycle as a metric for ecosystem instability. The rationale for using $\delta^{13} \mathrm{C}_{\text {carb }}$ perturbation is because the $\delta^{13} \mathrm{C}_{\mathrm{carb}}$ record is robust and at high resolution, and short term
(0.5-10 Myr) $\delta^{13} \mathrm{C}_{\text {carb }}$ variability over the past 1,000 Myr has been suggested to record ocean-atmosphere system instability (Rothman, 2017). The $\mathrm{CT}_{\text {index }}$ is calculated according to Equation 1:

$$
\mathrm{CT}_{\text {index }}(\mathrm{t})=\left(\frac{1}{N} \sum_{i=1}^{N}|F(i)-\mu(t)|^{n}\right)^{\frac{1}{n}}
$$

To measure the degree of carbon cycle turbulence at each point $\left(\mathrm{CT}_{\text {index }}(\mathrm{t})\right)$, over a pre-determined duration (e.g., $\tau_{\text {span }}=$ $0.05 \mathrm{Myr})$, we compiled all the datum points within the $\tau_{\text {span }}$ (centred on the calculating point, $\mathrm{t}$ ) in array F. In this case, $\mathrm{N}$ and $\mu(t)$ represent the number and average isotopic value of the array $\mathrm{F}$, respectively, where $\mathrm{n}$ is a statistical control to avoid a situation where the sum of the mean deviations is zero. When $\mathrm{n}=2$, the output of the calculation, $\mathrm{CT}_{\text {index }}(\mathrm{t})$, is equal to the standard deviation of the array $\mathrm{F}$ (see sensitivity tests for parameters $\tau_{\text {span }}$ and $\mathrm{n}$ in Supplementary Information). Thus, major positive and negative excursions will both result in a $\mathrm{CT}_{\text {index }}$ peak.

Phanerozoic biotic extinction rates (ERs) at the generic level were derived from a palaeobiology database (PaleoDB), and are applied to represent biodiversity changes and ecologic disturbance for comparison with $\mathrm{CT}_{\text {index }}$ values (Fig. 1). The fossil

1. State Key Laboratory of Geological Processes and Mineral Resources, China University of Geosciences, Wuhan 430074, China

2. State Key Laboratory of Biogeology and Environmental Geology, School of Earth Sciences, China University of Geosciences, Wuhan 430074, China

3. School of Earth and Environment, University of Leeds, Leeds, LS2 9JT, UK

4. Institute of Remote Sensing and Geographical Information Systems, School of Earth and Space Sciences, Peking University, Beijing, China

5. State Key Laboratory for Mineral Deposit Research, School of Earth Sciences and Engineering Frontiers Science Center for Critical Earth Material Cycling, Nanjing University, Nanjing 210023, China

Corresponding author (email: zhong.qiang.chen@cug.edu.cn; lszhao@cug.edu.cn) 


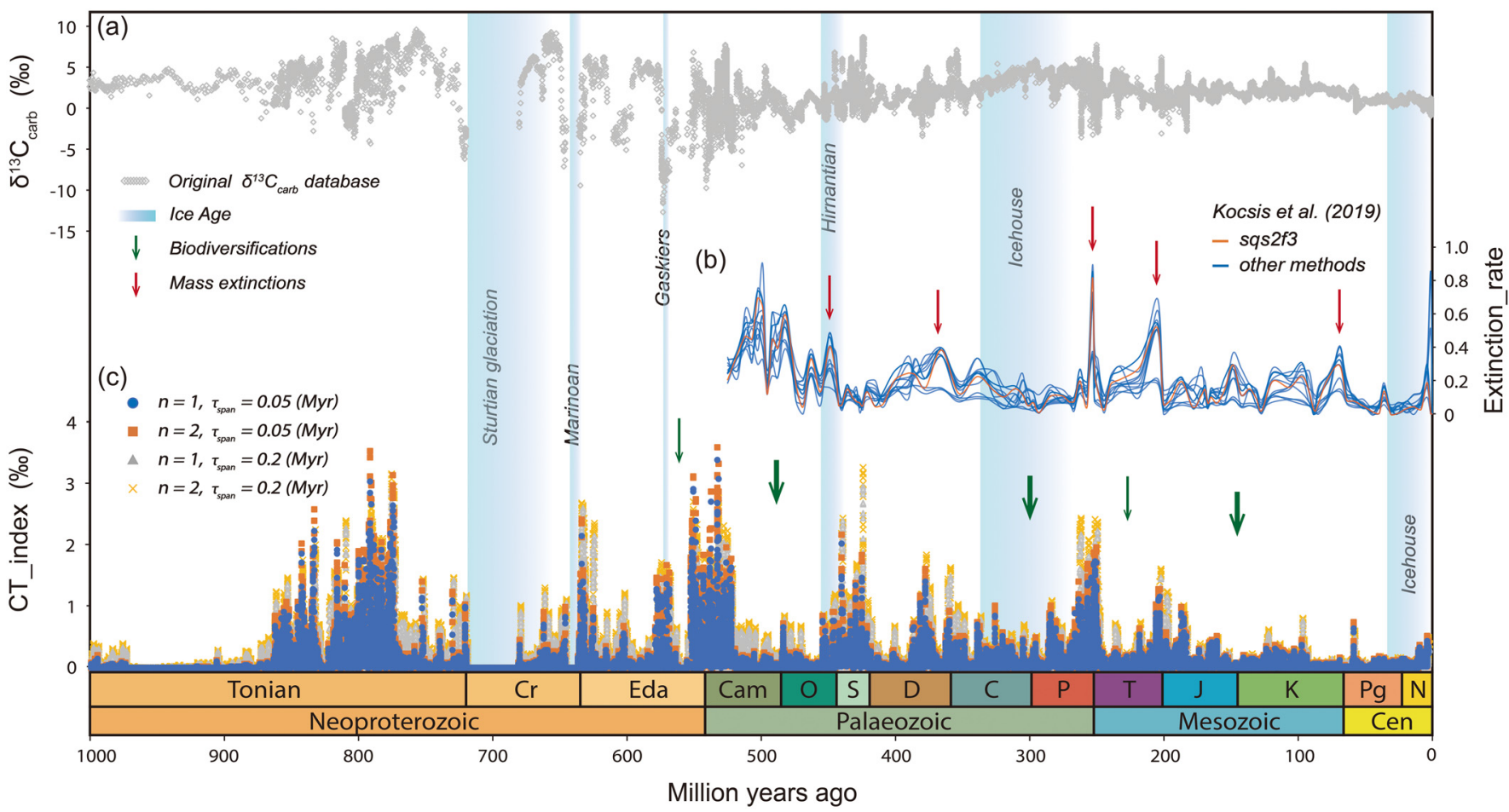

Figure $1 \delta^{13} \mathrm{C}_{\text {carb }}$ database (Cramer and Jarvis, 2020) and calculated $\mathrm{CT}_{\text {index }}$ values across the last 1,000 Myr, combined with calculated extinction rates through the Phanerozoic (from the palaeobiology database; http://www.paleobiodb.org/; Kocsis et al., 2019).

record often documents a direct link between enhanced ERs and dramatic reductions in biodiversity, or major ecologic disturbance, during mass extinctions (Alroy et al., 2008). Hence, relationships between $\mathrm{CT}_{\text {index }}$ peaks and higher $\mathrm{ER}$ values can be employed to investigate coincidence between catastrophic environmental stress and biotic crises through Earth history. Moreover, increasing evidence suggests that we are in the midst of a "sixth mass extinction" (Barnosky et al., 2011; Ceballos et al., 2015), and a pronounced negative excursion in $\delta^{13} \mathrm{CO}_{2}$ caused by greenhouse gas emissions has been recorded since the onset of the industrial revolution (Graven et al., 2020). In order to investigate the current and potential future significance of rising greenhouse gas emissions on biotic ERs, we compare the present day $\mathrm{CT}_{\text {index }}$ value to that observed during the Permian/Triassic (PTr) transition, representing the most severe mass extinction of the Phanerozoic.

\section{Results and Discussion}

$C T_{\text {index }}$ vs. environmental perturbations. Our reconstruction of the $\mathrm{CT}_{\text {index }}$ through time (Fig. 1; analytical methods and database details are given in the Supplementary Information) highlights that it is both the magnitude and duration of the carbon cycle perturbation that exhibits a major link to the extent of environmental and biotic change. The $\mathrm{CT}_{\text {index }}$ offers a unique measure of the intensity of $\delta^{13} \mathrm{C}_{\text {carb }}$ fluctuations, which reflect carbon cycle perturbation and the dynamic balance between the input of carbon and its burial as carbonate and organic matter (Kump and Arthur, 1999). As such, the $\mathrm{CT}_{\text {index }}$ peaks during the late Tonian, through the Cryogenian and Ediacaran glaciations, and into the Cambrian (Fig. 1), broadly correlate with periods of environmental oxygenation (Canfield et al., 2007; Lyons et al., 2021). The major variability evident in $\mathrm{CT}_{\text {index }}$ values (in both magnitude and frequency) reflects well documented instability in the extent of Earth surface oxygenation over this interval
(Canfield et al., 2008; Sahoo et al., 2016; He et al., 2019; Li et al., 2020).

As the Earth progressed to near modern levels of oxygenation in the Palaeozoic (Krause et al., 2018) and life continued to evolve and diversify (Lenton et al., 2016), the ensuing environmental stability generally resulted in lower peaks in $\mathrm{CT}_{\text {index }}$ values, with the exception of the major peak across the PTr boundary (Fig. 1). However, despite the general decrease, the $\mathrm{CT}_{\text {index }}$ trend is of sufficient resolution (see Fig. S-4) to distinguish nearly all of the major individual carbon cycle perturbations during the Phanerozoic (Fig. 1). Thus, although there are many potential controls on the $\delta^{13} C_{\text {carb }}$ record (Lenton et al., 2018), the $\mathrm{CT}_{\text {index }}$ provides an integrated and robust assessment of the overall extent of environmental perturbation.

Deciphering extinction rates and environmental perturbations. The $\mathrm{CT}_{\text {index }}$ trends correlate with biodiversity fluctuations, ERs and ecologic disturbance through the Neoproterozoic and Phanerozoic (Fig. 1). Several important intervals of biodiversification, including the initial evolution of the Ediacaran biota, the Cambrian explosion, the Great Ordovician Biodiversification, the Carboniferous-Permian, and the mid-Triassic and JurassicCretaceous radiations (Sepkoski, 1981; Alroy et al., 2008; Erwin et al., 2011; Darroch et al., 2018; Fan et al., 2020), all coincide with low $\mathrm{CT}_{\text {index }}$ values. By contrast, pronounced $\mathrm{CT}_{\text {index }}$ peaks correspond to higher ERs, as evident during mass extinctions (Fig. 1b).

However, since the datum sampling densities of $\delta^{13} \mathrm{C}_{\text {carb }}$ database and PaleoDB are clearly different, it is difficult to directly calculate the regression relationship between the $\mathrm{CT}_{\text {index }}$ and ERs. To address this, we begin by identifying significant global perturbation events during the Phanerozoic (Fig. S-4, Table S-2). These 41 events comprise the major $\delta^{13} C_{\text {carb }}$ perturbations (Rothman, 2017), mass extinctions (Bambach, 2006), and biodiversifications (Fan et al., 2020). While the $\mathrm{CT}_{\text {index }}$ trend reflects the degree of environmental perturbation on the timescale of individual events (Fig. S-3), consideration needs to be 

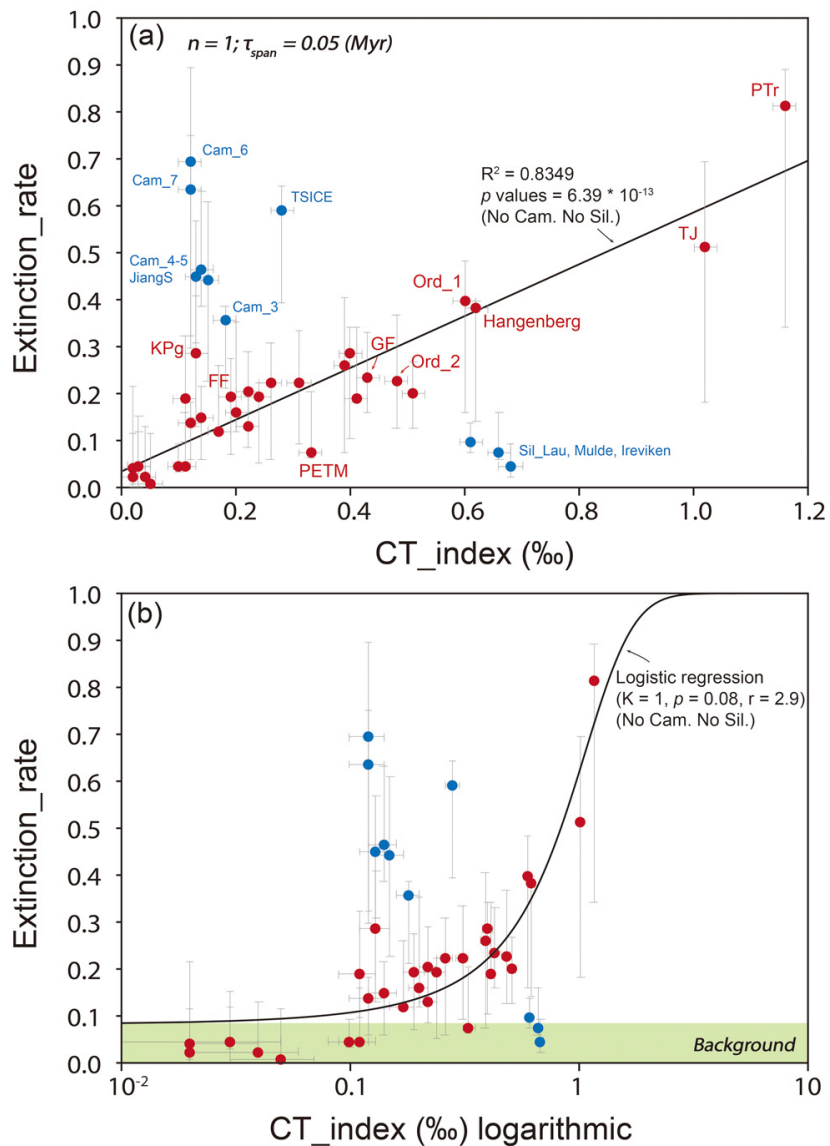

Figure 2 Cross plots of the extinction rate (ER) vs. the $\mathrm{CT}_{\text {index }}$ for 41 events. (a) Blue circles represent outlier events from the Cambrian and Silurian. Red circles represent the other events from the Phanerozoic, which show a strong correlation between ER and the $\mathrm{CT}_{\text {index }}$ (b) Logarithmic plot of the extinction rate (ER) vs. the $\mathrm{CT}_{\text {index }}$ for 41 events, with the best fit logistic regression curve of the red circles. See Table S-2 for details.

given to the method for calculating ER ratios. Kocsis et al. (2019) explored 12 different metrics to calculate ER values (Fig. 1b), which also consider the potential errors caused by the PaleoDB itself. For each stage, we use the maximum, minimum and 'sqs2f3' methods (Kocsis et al., 2019) to establish a broad range for the calculation of ER values (Fig. 2, Fig. S-5). Then, each major $\mathrm{CT}_{\text {index }}$ peak is considered responsible for the corresponding ER perturbation.

Cross plots show that the $\mathrm{CT}_{\text {index }}$ and $\mathrm{ER}$ values for 31 of these events are broadly positively correlated (red points; Fig. 2), with $\mathrm{R}^{2}=0.835$ and $p<0.001$. The remaining 10 events (blue points; Fig. 2) comprise two types of outlier: (1) events with high $\mathrm{ER}$ and low $\mathrm{CT}_{\text {index }}$ values, occurring from 541 to $480 \mathrm{Ma}$ (from the Cambrian to the first stage of the Ordovician), and (2) events with high $\mathrm{CT}_{\text {index }}$ and low ER values, occurring in Silurian. Given that the dataset for these latter two intervals is smaller than that of other periods of the Phanerozoic (Fig. S-4a), these outliers may result from the incompleteness of the PaleoDB. However, a fundamental difference in ecosystem stability for these periods, relative to the rest of the Phanerozoic, cannot be ruled out. Nevertheless, the $\mathrm{CT}_{\text {index }}$ suggests that environmental turbulence was intense during the early Cambrian (but not the middle to late Cambrian) and through the entire Silurian. While the high $\mathrm{ER}$ and low $\mathrm{CT}_{\text {index }}$ signal for 541-480 Ma may represent an unstable ecosystem, the high $\mathrm{CT}_{\text {index }}$ and low ER signal for the Silurian reflects a more stable ecosystem that did not suffer a major extinction.

Next, in order to explore the potential thresholds of the mass extinctions, we use a logistic curve (sigmoid curve) to fit the data (Fig. 2b), which is a widely used approach for deep time extinction studies (Roopnarine, 2006). Logistic curves represent the battle between ecosystem stability and environmental instability. Ecosystems are generally unaffected at low levels of volatility, but when the degree of volatility increases to a certain threshold, the biotic ER rapidly increases (e.g., the PTr and TJ mass extinctions)

In addition to distinguishing these well studied events, the logistic curve also provides new insight into broader trends through time. Here we note that a previous study of major $\delta^{13} \mathrm{C}_{\text {carb }}$ events suggests that the thresholds of catastrophe in the Earth system have not changed systematically over time (Rothman, 2017). Building on this, our data implicitly suggest that, although life has evolved into more complex forms, ecosystem tolerance to environmental turbulence has not significantly improved through time (discounting the Cambrian and Silurian; Fig. S-5c). This observation naturally leads to consideration of whether the $\mathrm{CT}_{\text {index }}$ may be used to evaluate the possible nature of Earth's "sixth mass extinction" in the modern and future environment.

Contrasting the $\mathrm{CT}_{\text {index }}$ during the PTr and from 1700 to 2100 A.D. Current high extinction rates of some taxonomic groups suggest that the Earth may be entering a "sixth mass extinction", which may have a causal relationship with increasing greenhouse gases in the atmosphere (Barnosky et al., 2011; Ceballos et al., 2015). However, there is still a widely recognised "last kilometre gap" between the fossil record and the modern bio-record and their extinction rates, for the following reasons: (1) most modern data focus on terrestrial vertebrates (e.g., mammals and birds), whereas the fossil record dominantly reflects marine invertebrates (e.g., brachiopods, gastropods and bivalves) (Kocsis et al., 2019), and (2) there are different time spans when considering a particular extinction. Specifically, the "Big Five" Phanerozoic mass extinctions are only constrained across a broad time resolution of millions of years, so a comparison with modern events occurring on a timescale of a hundred to a thousand years is not straightforward, and (3) there is uncertainty in the near future. For example, calculation of ERs for modern species is hampered since it remains unknown whether "critically endangered species" will actually go extinct (Barnosky et al., 2011). (4) Other unknowns, including continental configuration, pre-existing climate state, and the extant biota at the time of $\mathrm{CT}_{\text {index }}$ perturbation might also affect how the ER responds.

To address these issues, we note that if the core hypothesis of the $\mathrm{CT}_{\text {index }}$ stands, then the sixth mass extinction should be accompanied by a distinct $\mathrm{CT}_{\text {index }}$ peak. We thus reconstruct $\mathrm{CT}_{\text {index }}$ values from 1700 to 2100 A.D., representing the time period prior to, and after, the industrial revolution, and we contrast this with the PTr transition at $\sim 252 \mathrm{Ma}$, representing the most severe mass extinction of the Phanerozoic. We used $\delta^{13} \mathrm{CO}_{2}$ curves from ice core to reconstruct the modern $\mathrm{CT}_{\text {index }}$ trend due to its complete and robust record over the last several centuries, in addition to the availability of modelled near future values (Rubino et al., 2013; Graven et al., 2020). However, we note that other carbon hosts, including surface ocean dissolved inorganic carbon, coral samples, and $\mathrm{CH}_{4}$ in Antarctica ice core also sensitively record significant $\mathrm{CT}_{\text {index }}$ peaks (Fig. S-7). This approach is reinforced by an observed strong similarity in the $\mathrm{CT}_{\text {index }}$ output when calculated using the $\delta^{13} \mathrm{CO}_{2}$ and $\delta^{13} \mathrm{C}$ coral records (Fig. S-7). To further enhance the reliability of our comparison, we focus on a very short interval during the PTr 

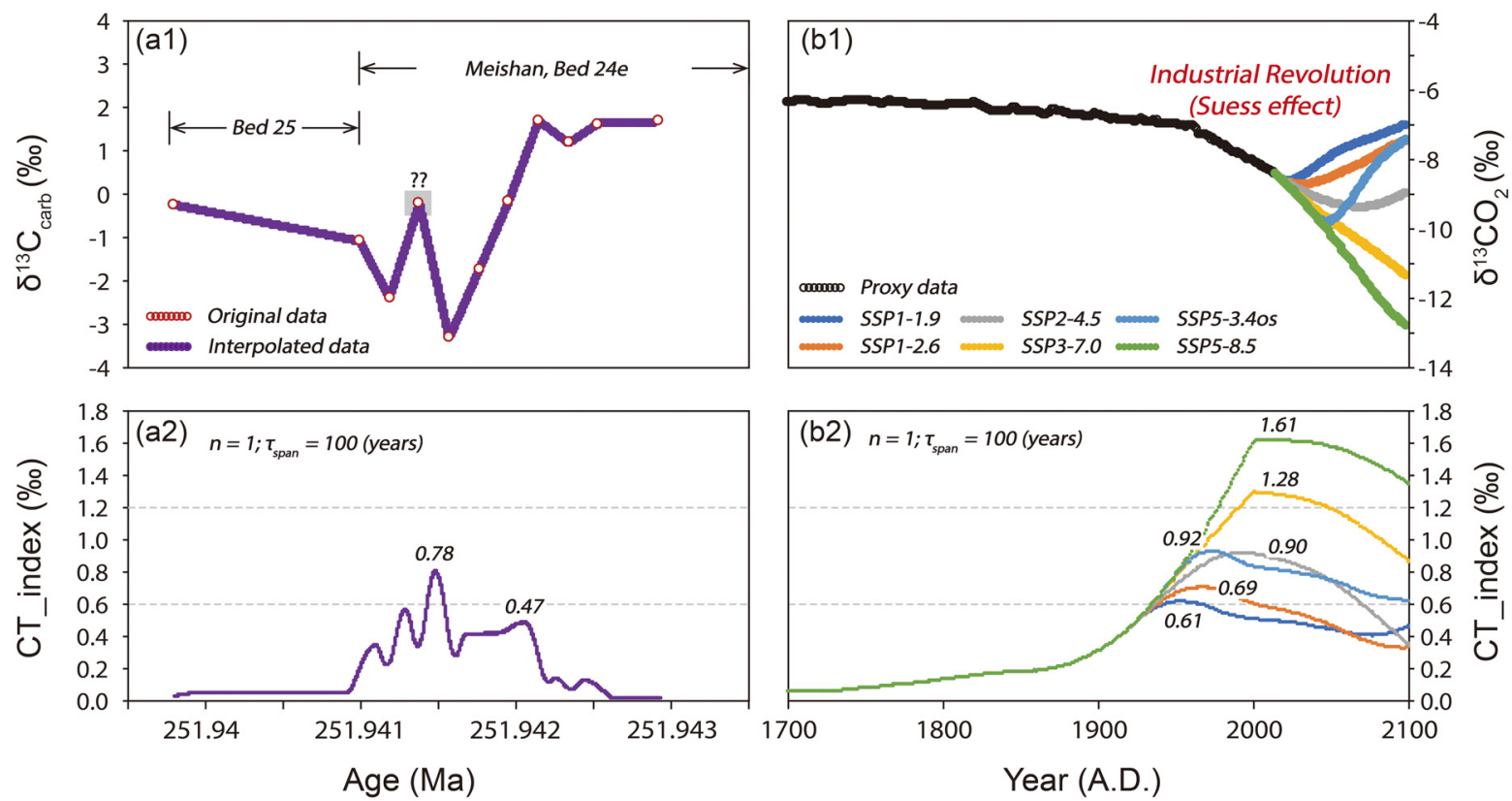

Figure 3 Comparison of $\delta^{13} \mathrm{C}_{\text {carb }}$ and $\delta^{13} \mathrm{CO}_{2}$ across the PTr mass extinction and the Industrial Revolution period, and the calculated $\mathrm{CT}_{\text {index }}$ (a) PTr dataset collected from bed 24e to 25, Meishan section (Burgess et al., 2014). (b) Industrial Revolution period (Rubino et al., 2013). The future $\delta^{13} \mathrm{CO}_{2}$ estimations are based on CMIP6 Scenario-MIP (Graven et al., 2020). All the original data were interpolated to a one point per year resolution; $\tau_{\text {span }}=0.0001 \mathrm{Ma}$ (100 year) and $n=1$ were employed to run the $C_{\text {index }}$.

transition, between Bed 24e to Bed 25 in the Meishan GSSP section, which documents the extinction level itself (Burgess et al., 2014). This interval has 11 original $\delta^{13} C_{\text {carb }}$ datum points across an estimated interval of $\sim 3,000$ years. Hence, we calculate the $\mathrm{CT}_{\text {index }}$ for both the PTr and the industrial revolution period using the same parameters $\left(n=1 ; \tau_{\text {span }}=100\right.$ years), and the datasets were pre-normalised to a datum density of one point per year.

The relative size of the $\mathrm{CT}_{\text {index }}$ peaks calculated under the same conditions for the two time intervals is of practical comparative significance (Fig. 3). The $\mathrm{CT}_{\text {index }}$ peak during the PTr ranges from 0.47 to 0.78 , whilst the $\mathrm{CT}_{\text {index }}$ peak of the industrial revolution period ranges from 0.61 to 1.61 , with the latter reflecting the predicted range for the $\delta^{13} \mathrm{CO}_{2}$ trend into the near future. If fossil fuel emissions peak at the present level and are at a low level through the next century, it has been suggested (Graven et al., 2020) that $\delta^{13} \mathrm{CO}_{2}$ may recover from $-8.8 \%$ o to $7.0 \%$, which leads to a moderate $\mathrm{CT}_{\text {index }}$ peak (line SSP1-1.9; Fig. 3). However, in other scenarios without such effective limits on fossil fuel emissions, $\delta^{13} \mathrm{CO}_{2}$ will likely continue to decrease through the next century (line SSP8.5), causing a dramatic peak in the $\mathrm{CT}_{\text {index }}$ that may be even greater than the $\mathrm{PTr}_{\mathrm{CT}} \mathrm{C}_{\text {index }}$ peak (Fig. 3). While the current extinction of species is driven by biodiversity loss that is only partly associated with fossil fuel driven climate change, the empirical relationship between ecosystem stability and biotic ERs implies that, if fossil fuel emissions are not significantly decreased, Earth's "sixth mass extinction" has the potential to be severe.

\section{Acknowledgements}

The contributors to the PaleoDB database and Geologic Time Scale are thanked for their provision of taxonomic and carbon isotope data for the database. We are grateful to Gavin Foster and two anonymous reviewers for their comments, which greatly improved this manuscript. This study was supported by five NSFC grants (41821001, 41930322, 41977264, 42073002,
92055212), and by 111 Project of China (BP0820004). ZL is funded by the Fundamental Research Funds for National Universities, China University of Geosciences (Wuhan).

Editor: Gavin Foster

\section{Additional Information}

Supplementary Information accompanies this letter at https:// www.geochemicalperspectivesletters.org/article2137.

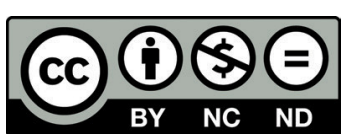

(C) 2021 The Authors. This work is distributed under the Creative Commons Attribution NonCommercial No-Derivatives 4.0 License, which permits unrestricted distribution provided the original author and source are credited. The material may not be adapted (remixed, transformed or built upon) or used for commercial purposes without written permission from the author. Additional information is available at https://www. geochemicalperspectivesletters.org/copyright-and-permissions.

Cite this letter as: Li, Z.-H., Guo, Z., Chen, Z.-Q., Poulton, S.W., Bao, Y., Zhao, L., Zhang, F.-F. (2021) A novel carbon cycle turbulence index identifies environmental and ecological perturbations. Geochem. Persp. Let. 20, 11-15. https://doi.org/10.7185/ geochemlet.2137

\section{References}

Alroy, J., Aberhan, M., Bottjer, D., Foote, M. Fursich, F.T. Harries, P.J. Hendy, A.J.W., Holland, S.M., Lvany, L.C., Kiessling, W., Kosnik, M.A., Marshall, C.R., McGowan, A.J., Miller, A.I., Olszewski, T.D., Patzkowsky, M.E., Peters, S.E., Villier, L., Wagner, P.J., Bonuso, N., Borkow, P.S., Brenneis, B., Clapham, M.E., Fall, L.M., Ferguson, C.A., Hanson, V.L., Krug, A.Z., Layou, K.M., Leckey, E.H., Nurnberg, S., Powers, C.M., Sessa, J.A., Simpson, C., Tomasovych, A., Visaggi, C.C. (2008) Phanerozoic Trends in the Global Diversity of Marine Invertebrates. Science 321, 97-100. 
Bambach, R.K. (2006) Phanerozoic Biodiversity Mass Extinctions. Annual Review of Earth and Planetary Sciences 34, 127-155.

Barnosky, A.D., MatzKe, N., TOMiya, S., Wogan, G.O.U., SwartZ, B., Quental, T.B., Marshall, C., McGuire, J.L., Lindsey, E., Maguire, K.C., Mersey, B., FERRER, E.A. (2011) Has the Earth's sixth mass extinction already arrived? Nature 471, 51-57.

Burgess, S.D., Bowring, S., SHEN, S. (2014) High-precision timeline for Earth's most severe extinction. PNAS 111, 3316-3321.

Canfield, D.E., Poulton, S.W., Narbonne, G.M. (2007) Late-Neoproterozoic Deep-Ocean Oxygenation and the Rise of Animal Life. Science, New Series 315, 92-95.

Canfield, D.E., Poulton, S.W., Knoll, A.H., Narbonne, G.M., Ross, G. Goldberg, T., Strauss, H. (2008) Ferruginous Conditions Dominated Later Neoproterozoic Deep-Water Chemistry. Science 321, 949-952.

Ceballos, G., Ehrlich, P.R., Barnosky, A.D., García, A., Pringle, R.M., Palmer, T.M. (2015) Accelerated modern human-induced species losses: Entering the sixth mass extinction. Science Advances 1, e1400253.

Chen, Z.-Q., BEnTon, M.J. (2012) The timing and pattern of biotic recovery following the end-Permian mass extinction. Nature Geoscience 5, 375-383.

Cramer, B.D., Jarvis, I. (2020) Chapter 11 - Carbon Isotope Stratigraphy. In Gradstein, F.M., OGG, J.G., Schmitz, M.D., OGg, G.M. (Eds.) The Geologic Time Scale 2020. Elsevier, Amsterdam, 309-343. doi: 10.1016/ B978-0-12-824360-2.00011-5.

Darroch, S.A.F., Smith, E.F., Laflamme, M., Erwin, D.H. (2018) Ediacaran Extinction and Cambrian Explosion. Trends in Ecology \& Evolution 33, $653-663$.

Erwin, D.H., Laflamme, M., Tweedt, S.M., Sperling, E.A., Pisani, D., Peterson, K.J (2011) The Cambrian Conundrum: Early Divergence and Later Ecological Success in the Early History of Animals. Science 334, 1091-1097.

FAN, J.X., Shen, S.Z., ERwin, D.H., SAdler, P.M., Macleod, N., ChEnG, Q.M., Hou, X.D., Yang, J., WANG, X.D., Wang, Y., Zhang, H., Chen, X., Li, G.X., Zhang, Y.C., ShI, Y.K., Yuan, D.X., Chen, Q., Zhang, L.N., LI, C., ZHAO, Y.Y. (2020) A high-resolution summary of Cambrian to Early Triassic marine invertebrate biodiversity. Science 367, 272-277.

Graven, H., Keeling, R.F., Rogelj, J. (2020) Changes to Carbon Isotopes in Atmospheric CO2 Over the Industrial Era and Into the Future. Global Biogeochemical Cycles 34, e2019GB006170.

He, T.C., Zhu, M.Y., Mills, B.J.W., Wrnn, P.M., Zhuravlev, A.Y., Tostevin, R., Pogge Von Strandmann, P.A.E., Yang, A.H., Poulton, S.W., Shields, G.A. (2019) Possible links between extreme oxygen perturbations and the Cambrian radiation of animals. Nature Geoscience 12, 468-474.

Kocsis, A.T., Reddin, C.J., Alroy, J., Kiessling, W. (2019) The r package divDyn for quantifying diversity dynamics using fossil sampling data. Methods in Ecology and Evolution 10, 735-743.

Krause, A.J., Mills, B.J.W., Zhang, S., Planavsky, N.J., Lenton, T.M., Poulton, S.W (2018) Stepwise oxygenation of the Paleozoic atmosphere. Nature Communications 9, 4081

KUMP, L.R., ARTHUR, M.A. (1999) Interpreting carbon-isotope excursions: carbonates and organic matter. Chemical Geology 161, 181-198.

LENTON, T.M., DAINES, S.J. (2018) The effects of marine eukaryote evolution on phosphorus, carbon and oxygen cycling across the ProterozoicPhanerozoic transition. Emerging Topics in Life Sciences 2, 267-278.

Lenton, T.M., Dahl, T.W., Daines, S.J., Mills, B.J.W., Ozaki, K., Saltzman, M.R. PORADA, P. (2016) Earliest land plants created modern levels of atmospheric oxygen. PNAS 113, 9704-9709.

Li, Z., CaO, M., Loyd, S.J., Algeo, T.J., ZhaO, H., Wang, X., ZhaO, L., Chen, Z.-Q. (2020) Transient and stepwise ocean oxygenation during the late Ediacaran Shuram Excursion: Insights from carbonate $8238 \mathrm{U}$ of northwestern Mexico. Precambrian Research 344, 105741.

Lyons, T.W., Diamond, C.W., Planavsky, N.J., Reinhard, C.T., Li, C. (2021) Oxygenation, Life, and the Planetary System during Earth's Middle History: An Overview. Astrobiology 21, 906-923.

Payne, J.L, Bachan, A, Heim, N.A, Hull, P.M, Knope, M.L. (2020) The evolution of complex life and the stabilization of the Earth system. Interface Focus 10, 20190106

RoopNARINE, P.D. (2006) Extinction cascades and catastrophe in ancient food webs Paleobiology 32, 1-19.

Rothman, D.H. (2017) Thresholds of catastrophe in the Earth system. Science Advances 3, e1700906.

Rubino, M., Etheridge, D.M., Trudinger, C.M., Allison, C.E., Battle, M.O Langenfelds, R.L., Steele, L.P. Curran, M., Bender, M., White, J.W.C., Jenk, T.M., Blunier, T., Francey, R.T. (2013) A revised 1000 year atmospheric $813 \mathrm{C}-\mathrm{CO} 2$ record from Law Dome and South Pole, Antarctica. Journal of Geophysical Research: Atmospheres 118, 8482-8499.

Sahoo, S.K., Planavsky, N.J., Jiang, G., Kendall, B., Owens, J.D., Wang, X., Shi, X., AnBar, A.D., Lyons, T.W. (2016) Oceanic oxygenation events in the anoxic Ediacaran ocean. Geobiology 14, 457-468.

SEPKOSKI, J.J. (1981) A factor analytic description of the Phanerozoic marine fossil record. Paleobiology 7, 36-53. 